\title{
A localização dos atores do sistema de inovaçáo brasileiro e seus impactos regionais na década de 2000
}

Ulisses dos Santos. Universidade Federal de Minas Gerais, Belo Horizonte, Brasil. Philipe Mendes. Universidade Federal de Minas Gerais, Belo Horizonte, Brasil.

RESUMo | A literatura sobre sistemas de inovação e desenvolvimento regional observa a existência de impactos positivos da proximidade geográfica entre atividades econômicas e estruturas de ciência e tecnologia. Frente a essa observação, o presente trabalho avalia se a localização de atores do sistema brasileiro de inovação favorece as atividades econômicas locais em microrregiôes do país. Os resultados empíricos indicam que o setor industrial das microrregióes observadas é positivamente influenciado pela presença de entes do sistema de inovação. Isso sugere que o processo recente de expansão do sistema de inovação no Brasil tende a gerar importantes efeitos sobre as estruturas produtivas regionais, principalmente, sobre a indústria. Para o setor serviços não foram observados impactos estatisticamente significantes, embora os dados indiquem que a presença de tais atores também favorece o setor.

PALAVRas CHAVE | desenvolvimento regional e local, distribuição espacial, inovação tecnológica.

ABSTRACT | The literature on innovation systems and regional development points at the existence of positive impacts of geographical proximity of scientific and technological structures over economic activities. Based on this observation this paper aims to evaluate the effects of the localization of Brazilian innovation system actors over local economic activities. The econometric results show that the industry sector is positively affected by the presence of those actors in the same region. These results suggest that the late expansion in Brazilian innovation system may have important effects over regional productive structures, mainly over industry. For the tertiary sector statistically significant impacts were not found. Nevertheless, the data suggest that the regional presence of the innovation system actors favors the sector.

KEYwORDs | regional and local development, spatial distribution, technological innovation. 


\section{Introduçáo}

O Brasil passou ao longo da década de 2000 por um processo de expansão de seu Sistema Nacional de Inovação, que resultou na ampliação de sua abrangência territorial. Houve um aumento no número de instituiçóes de ensino e pesquisa e nas produçóes científica e tecnológica, como também um processo de redistribuição espacial dessas, contemplando um conjunto ampliado de localidades perante ao território nacional. Esse processo alterou uma tendência histórica de concentração dos ativos de ciência e tecnologia (C\&T) nas áreas de maior desenvolvimento econômico no país (Santos, 2014). A partir da literatura acerca das relaçóes entre os sistemas de inovação e o desenvolvimento regional, acredita-se que tal processo possa ser benéfico para a dinâmica dos setores produtivos, dado que a proximidade geográfica em relação a uma estrutura de ciência e tecnologia geraria spillovers positivos sobre as atividades econômicas da regiáo (Audretsch \& Feldman, 1996; Cooke, 1998; Jaffe, 1989).

À luz dessa perspectiva, o presente artigo tem como objetivo avaliar a existência de impactos da localização de atores do Sistema Nacional de Inovaçáo sobre a dinâmica das atividades econômicas regionais no Brasil. Em linhas gerais, tenta-se verificar se a existência numa dada regiáo de tais atores é, de fato, benéfica para as atividades econômicas nela localizadas. Para isso é adotado aqui um indicador capaz de sumarizar informaçôes relativas ao grau de desenvolvimento das estruturas microrregionais do Sistema Nacional de Inovaçáo, o Índice de Desenvolvimento Regional do Sistema de Inovaçáo (IDRSI), proposto inicialmente por Santos (2014). Esse indicador é confrontado com dados relativos à dinâmica econômica dos setores indústria e serviços para as 558 microrregiôes brasileiras a partir de estimaçôes econométricas. A escala territorial adotada para a análise, a microrregional, é definida pelo Instituto Brasileiro de Geografia e Estatística (IBGE). Segundo essa definição, tal escala reflete uma agregação territorial formada por municípios contíguos geograficamente e que apresentam especificidades em comum. Tais especificidades consideradas na organização do espaço microrregional se referem à estrutura produtiva e às relaçóes econômicas dela decorrentes. Considera-se, portanto, aspectos ligados às relaçóes de produção, distribuição e consumo (IBGE, 1990). A opção pela escala microrregional se justifica por tratar de um nível de agregação superior ao municipal, dado que se acredita que a estrutura de C\&T de um município seja capaz de gerar transbordamentos sobre seus vizinhos mais próximos.

Além do grau de desenvolvimento das estruturas microrregionais, de C\&T, são utilizadas variáveis de controle com vistas a avaliar determinantes da dinâmica dos setores, incluindo variáveis relativas aos possíveis efeitos do desempenho de localidades vizinhas sobre a indústria e os serviços das microrregióes analisadas.

Busca-se com este trabalho, portanto, preencher uma lacuna na literatura acerca dos sistemas de inovaçáo e o desenvolvimento regional no Brasil, de modo a observar como a localização de estruturas de c\&T pode influenciar a dinâmica econômica das regióes no país. Trata-se de um aspecto altamente relevante dado o processo recente de ampliação no número de universidades e centros de pesquisa no Brasil, com a sua interiorização. 
A sequência deste artigo é composta por cinco seçôes, além desta introdução. A segunda seção apresenta aspectos teóricos sobre os sistemas de inovação e o desenvolvimento regional. A terceira seção aborda a evoluçáo regional do sistema brasileiro de inovaçáo entre os anos de 2000 e 2010. A quarta e a quinta seçóes tratam da análise econométrica realizada para este artigo, sendo apresentados, respectivamente, aspectos relativos à metodologia e os resultados dos exercícios empíricos. A última seção apresenta as consideraçôes finais do trabalho.

\section{Sistemas de inovação e desenvolvimento regional}

O sistema nacional de inovação ( $\mathrm{SNI}$ ) é formado por um conjunto de instituições formais e informais que promovem os processos de inovação tecnológica, sendo o grau de interação entre elas determinado pelo ambiente em que estão inseridas (Johnson, 1995). Trata-se de uma rede composta por instituiçóes pertencentes às esferas pública e privada que atuam de modo a criar, importar, modificar e difundir novas tecnologias por meio de suas atividades e interaçôes (Freeman, 1987). O sNI é composto, portanto, pelos atores econômicos, sociais, políticos, organizacionais, e institucionais que têm relevância para a difusão e uso das inovaçóes tecnológicas (Edquist, 2005).

Os objetivos principais de um sistema de inovação são: i) a realização de pesquisa e desenvolvimento; ii) a construção de competências internas por meio de qualificação e treinamento; iii) o suporte às interaçôes necessárias para o processo inovativo e iv) a criação, ou mudança, de instituiçóes eliminando obstáculos e dando suporte à inovação, à incubação e ao financiamento de atividades de inovação, dentre outros (Edquist, 2005). Com isso, é possível mencionar dentre os componentes do SNI atores como as universidades, institutos de pesquisa públicos e privados, centros de P\&D empresariais e agências governamentais, além das empresas.

A definição do conceito de sNI parte do entendimento que um sistema é constituído não apenas por um determinado conjunto de agentes, mas também pelo relacionamento entre estes, o que determina seu grau de desenvolvimento e suas potencialidades (Lundvall, 1995). A inovação tecnológica é, dessa forma, identificada como um processo social que é impulsionado pela existência desse conjunto de agentes e instituiçóes, que, uma vez alinhados às trajetórias tecnológicas vigentes, interagem com vistas a facilitar o seu desenvolvimento. Esses agentes integrantes de um determinado sistema de inovação se caracterizariam pela participação num processo conjunto de aprendizado onde a constante troca de informaçóes originaria um mecanismo de causação circular, pelo qual cada um desses influenciaria os demais (Lundvall, 1995). Trata-se, portanto, de um processo que pressupóe a existência de externalidades partindo de determinados elementos do SNI e atuando sobre os outros, acabando por influenciar o desenvolvimento de um processo de inovação.

Nesse sentido, pode-se considerar de extrema importância a capacidade de comunicação e interaçáo entre todos os agentes constituintes do SNI. Tanto as instituiçóes voltadas para atividades relacionadas à ciência e à tecnologia quanto àquelas que compóem o setor produtivo devem se esforçar na sustentação de fluxos 
informacionais, para que seja assegurado o sucesso do processo de inovação em todas as suas facetas. Dado isto, num sistema de inovação bem desenvolvido, as empresas e os agentes que as ajudam a promover a inovaçáo devem interagir estabelecendo tais fluxos de informação, sustentando o devido alinhamento entre o conhecimento científico e o conhecimento técnico.

Acredita-se, por isso, que aspectos espaciais, territoriais e regionais guardam importante relação com o processo de inovação tecnológica, especialmente no que tange a estes fluxos informacionais entre os diversos agentes que participam dos processos de produção científica e tecnológica (Asheim \& Gertler, 2005; Cooke, 1998, 2001; Jaffe, 1989). A proximidade geográfica, associada à partilha de elementos sociais e culturais, facilitaria e reforçaria tais fluxos de modo a impulsionar a inovação nos setores produtivos. Nesse sentido, além das organizaçóes, das firmas, das interaçóes e das relaçôes de aprendizado para a atividade inovativa, apontadas por autores como Freeman (1987, 1995), Lundval (1995), Nelson e Rosenberg (1993) como os principais determinantes da atividade de inovação, deve-se considerar também a importância de elementos regionais para esse processo (Cooke, 1998).

Dentre os neoschumpeterianos responsáveis por introduzir o conceito de sistema de inovação, Freeman $(1987 ; 2002)$ foi o primeiro a apontar a importância de políticas regionais sobre os processos de catch up. Ao tratar das políticas de desenvolvimento econômico no Japão, o autor ressaltou o esforço governamental na criação e execução de políticas regionais baseadas na ciência, educação, comunicaçôes e infraestrutura. O objetivo de tais políticas seria levar capacitaçóes técnicas a todo o território nacional de modo a integrar aos circuitos tecnológicos e científicos o maior número possível de agentes, independente de sua localização ou escala econômica (Freeman, 1987, p. 36).

Acerca das regiốes subnacionais, o autor observa que a aglomeração das atividades industriais teria importantes repercussôes sobre o seu desenvolvimento, em razão das economias de aglomeração marshallianas (Freeman, 2002). Desta forma, remete a aspectos amplamente difundidos no âmbito da economia regional ao chamar a atenção para a tendência das atividades econômicas em se aglomerarem no espaço.

No âmbito da economia regional, o conceito de Sistemas Regionais de Inovação (SRI) foi introduzido por Cooke (1992), partindo da influência neoschumpeteriana. Tal conceito deve ser entendido como uma síntese dos desenvolvimentos acerca da relação entre inovação tecnológica e o desenvolvimento regional e os sNis. Deve-se considerar que a busca por estratégias para o desenvolvimento regional por meio a atividade inovativa originou uma série de estudos, teorias e políticas entre as décadas de 1980 e 1990. Dentre os conceitos oriundos deste período, e que contribuíram para o desenvolvimento de um conceito de SRIs, é possível mencionar os de complexos tecnológicos regionais, parques tecnológicos, redes tecnológicas, tecnopolos, milieu inovativo, entre vários outros. Todos estes relacionavam a ascensão da inovação tecnológica a aspectos regionais (Cooke, 1998). Na medida em que tais conceitos, explorados predominantemente por cientistas regionais, foram atrelados aos esforços teóricos acerca dos sistemas nacionais de inovação, baseados principalmente em Freeman (1987; 1995) e Lundvall (1995), ganhou forma o conceito de SRIs (Cooke, 1998). Trata-se, então, 
de um conceito inspirado na ideia de sNIs, mas com ênfase em sistemas de inovação regionalmente delimitados (Asheim \& Gertler, 2005).

Assim como os sistemas nacionais de inovação, os sistemas regionais estão baseados na existência de um corpo institucional e nas interaçôes entre os agentes que o compóem. Porém, esta perspectiva agrega à análise aspectos mais comuns à economia regional, principalmente aqueles atrelados aos efeitos da proximidade entre os agentes no estabelecimento de suas relaçôes. Podem ser mencionados, nesse sentido, fatores ligados à imersão regional dos agentes num mesmo cenário local como facilitadores das interaçóes necessárias para o bom andamento do processo inovativo (Cooke, 2001).

O conceito de SRIs pondera que a geografia não é incidental, mas sim fundamental para a ascensão das inovaçóes, e assume a distribuição desigual do conhecimento no espaço (Asheim \& Gertler, 2005). Nesse sentido, as diferenças em termos da capacidade inovativa das regióes seriam resultantes da existência de diferentes trajetórias de aprendizagem regional imersas em sistemas institucionais diferenciados (Isaksen, 2001). Portanto, a compreensão das especificidades regionais marcadas pela proximidade espacial dos agentes e a sua interação na condução da inovação, de fato, importariam para o devido entendimento dos fatores que a favorecem. O SRI pode ser definido como a infraestrutura institucional para o suporte da atividade de inovação em meio à estrutura produtiva de uma determinada região (Asheim \& Gertler, 2005). Pode-se dizer que a consolidação de um SRI estaria atrelada à existência de quatro conjuntos de elementos fundamentais. Seriam eles; as firmas, as instituiçóes públicas e privadas, a infraestrutura de conhecimento e a política de inovação (Doloreux, 2002). Nesse cenário, o conjunto de firmas compondo uma aglomeração produtiva regionalmente identificada, o conjunto de instituiçôes voltadas para a produção e difusão do conhecimento científico-tecnológico, e as relaçôes interativas entre estas duas esferas seriam os principais determinantes do dinamismo e desenvolvimento para um SRI (Isaksen, 2001). A viabilização dessas interaçóes seria o principal foco das instituiçôes e políticas voltadas para a promoção da inovação.

Uma vez estabelecidos e disseminados os conceitos de SNI e SRI, ascende uma questão relativa às possíveis relaçóes entre eles. Ou seja, faz-se necessário considerar se os sistemas nacionais e subnacionais de inovação apresentam características concorrentes ou complementares. Quanto a isso, Freeman (2002), motivado pelas mudanças na economia mundial, tratou da importância de se identificar e interpretar as relaçóes entre os sistemas continental, nacional e subnacional de inovação. O autor ressalta o ganho de importância das escalas subnacionais nos estudos acerca da inovação, apontando a necessidade de entendimento das relaçóes de complementariedade e concorrência entre estas distintas escalas para as novas possibilidades de desenvolvimento tecnológico e econômico. Freeman (2002) chama a atenção, então, ao fato de que as vantagens regionais oriundas da aglomeração seriam influenciáveis por fatores ligados à escala nacional. Fatores como a cultura, política, economia e instituiçôes tecnológicas nacionais teriam importante influência sobre tais benefícios regionais dos quais as atividades territorialmente aglomeradas se aproveitariam. Logo, tais aspectos de natureza nacional poderiam limitar ou ampliar os benefícios 
da aglomeração regional. Por isso, Freeman (2002) identifica uma relação de complementaridade entre os sistemas nacional e subnacional de inovação.

Os SRIs são, por isso, considerados parte integrante do SNI, assumindo-se que cada região pode apresentar uma trajetória tecnológica própria que pode determinar o sucesso ou fracasso das políticas nacionais de ciência e tecnologia. Considera-se, portanto, que estruturas locais de ciência e tecnologia originárias de políticas e esforços nacionais podem apresentar variaçóes em seu nível de desenvolvimento, de acordo com a sua localização geográfica, o que estaria relacionado às diferentes trajetórias tecnológicas regionais e às bases de conhecimento locais (Asheim \& Gertler, 2005; Oinas \& Malecki, 1999).

De forma similar, acredita-se que uma região em que se localizem alguns dos principais atores do SNI tenderia a se desenvolver mais, já que estaria em vantagem na atração de novas indústrias, em razão de sua melhor estrutura de ciência e tecnologia. Isso, por sua vez, culminaria no crescimento da produção e da renda internas, assim como da sua arrecadação. A maior capacidade econômica destas regiôes possibilitaria a elas o reinvestimento em sua infraestrutura regionalizada de aprendizagem e conhecimento, a qual poderia impulsionar o sistema regional de inovação em questão, ampliando sua competitividade interna e externamente (Asheim, 1996; Florida, 1995). Deste modo, tais regiōes teriam maiores condições de alcançarem o desenvolvimento regional. Por sua vez, regióes que não contem com o mesmo investimento do governo nacional na instalação de atores do SNI em seus limites geográficos teriam menores possibilidades de promoção de inovaçóes tecnológicas, o que limitaria sua competitividade e, consequentemente, suas possibilidades de desenvolvimento. Logo, a distribuição espacial dos entes do SNI teria implicaçôes sobre a desigualdade de desenvolvimento entre as regiôes nacionais.

Com isso, acredita-se que a análise regional do SNI seja fundamental para o entendimento das diferenças de desenvolvimento econômico entre as regióes subnacionais. Na sequência desse trabalho, assume-se que a distribuição espacial do SNI pode ser um fenômeno ligado ao grau de desenvolvimento econômico regional.

\section{A evoluçáo regional do Sistema Brasileiro de Inovação}

A formação econômico-industrial do Brasil é marcada pela concentração de seus ativos mais dinâmicos nas regióes sudeste e no sul do país, sendo estas, consequentemente, as suas regiốes mais ricas (Furtado, 1976). Estas concentravam em 2000, $75,4 \%$ do рів brasileiro, percentual esse que permanecia ainda superior a $70 \% \mathrm{em}$ 2010. Como é possível observar, por meio da figura 1, esse quadro se materializa em diferenciais de renda entre as regióes do Brasil, o que é observável pelo PIB microrregional, para o qual as localidades pertencentes em estados das regióes Sul e Sudeste apresentam valores mais elevados. Embora as últimas décadas tenham mostrado uma tendência ao aumento da participação de outras regióes na produção e na renda nacionais, a desigualdade regional ainda é uma característica marcante da economia brasileira.

Esse aspecto foi fundamental para a distribuição territorial dos entes do SNI brasileiro, os quais se concentraram historicamente nas principais cidades das regióes Sul 
e Sudeste (Albuquerque, Simóes, Baessa, Campolina, \& Silva, 2002). A demanda por infraestrutura e trabalhadores qualificados induziu a realização de investimentos orientados para a criação das instituiçóes de ensino e pesquisa nas localidades de maior desenvolvimento industrial, que serviram como bases para a formaçáo do sistema brasileiro de inovação. Trata-se de um processo de causação circular em que regióes mais ricas acabam sendo beneficiadas com investimentos estatais orientados a atender às demandas de seus setores produtivos e, por isso, tendem a prosperar mais nos ciclos seguintes, dado que tendem a ser mais suscetíveis a se beneficiar dos progressos tecnológicos. Ou seja, há uma tendência à perpetuação da concentração regional da renda atrelada à distribuição dos ativos de ciência e tecnologia no território nacional. Um desdobramento desse processo é a concentraçáo espacial da atividade tecnológica no Brasil, refletido na participação das duas regióes nos depósitos de patentes junto ao Instituto Nacional de Propriedade Industrial para os anos de 2000 , igual a $81 \%$, e $2010,87,5 \%$ (Santos, 2014).

FIGURA I | PIB microrregional do Brasil 2010 (Reais R\$ a preços de 2000)

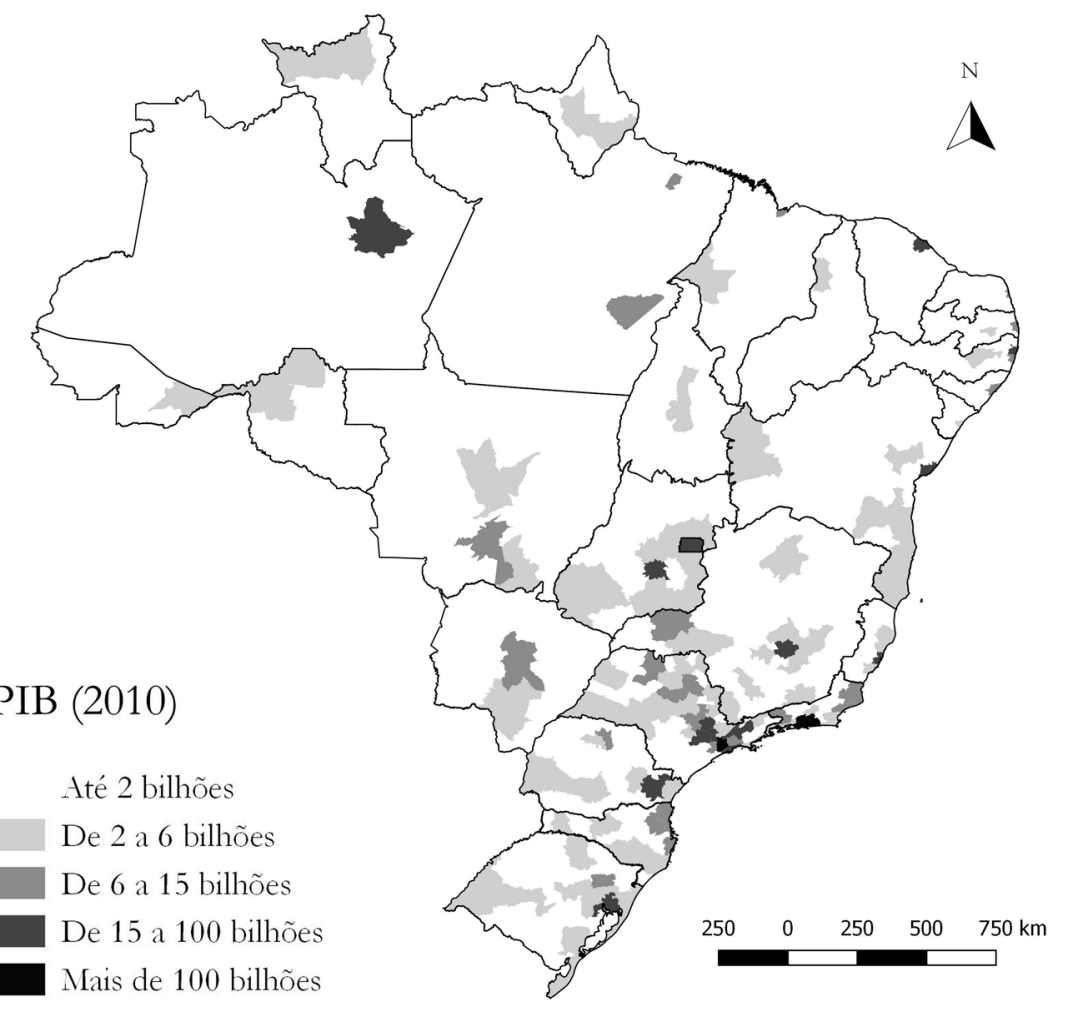

FONTE ELABORAÇÃO PRÓPRIA A PARTIR DE DADOS DO IPEADATA 
Considerando as microrregiôes brasileiras, é possível destacar que menos da metade delas se encontra nas regióes historicamente beneficiadas pela localização dos ativos industriais e de c\&T. Das 558 microrregiôes do país, 254 estão em estados pertencentes ao eixo sul-sudeste. A figura 2, abaixo ilustra a participação das microrregióes do país na produção tecnológica nacional. Nela é possível observar, por meio de dados relativos aos depósitos de patentes junto ao INPI, a concentração de microrregióes com atividades tecnológicas justamente nas áreas mais ricas do país. A comparação entre as figuras 1 e 2 sugere que a distribuição territorial da atividade tecnológica no Brasil segue o padrão de distribuição da renda.

FIGURA 2 Distribuição dos depósitos de patentes por milhão de habitantes por microrregióes brasileiras - 2000 - 2010
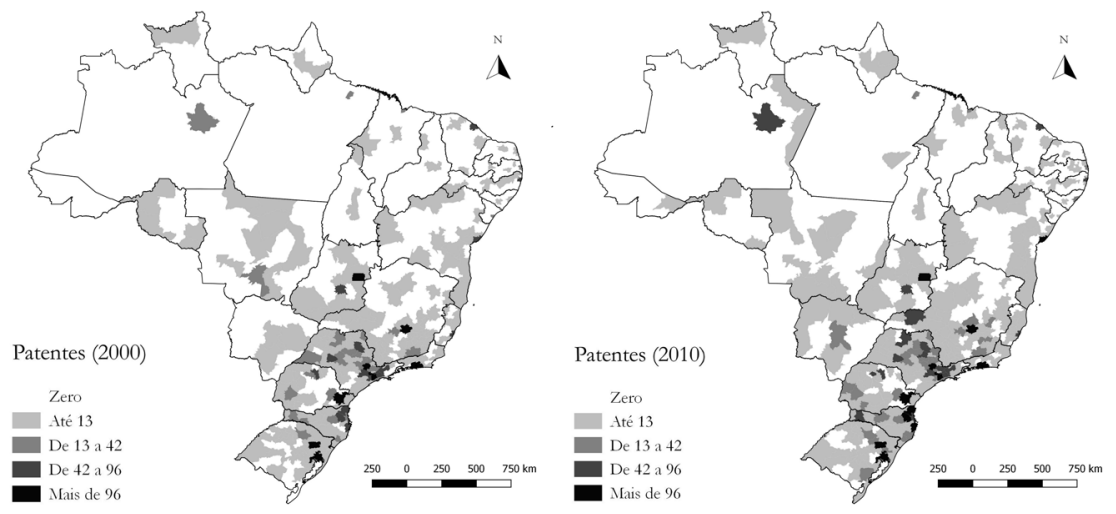

FONTE ELABORAÇÃO PRÓPRIA A PARTIR DE DADOS DO INIP

No entanto, deve-se observar que o SNI brasileiro passou, no período entre os anos de 2000 e 2010, por um processo de expansão, sendo essa pautada, sobretudo, nos avanços do seu sistema de ensino e pesquisa. Nesse sentido, foi possível identificar crescimento em indicadores que se referem a essa faceta do SNI, como o número de artigos científicos publicados em periódicos de abrangência internacional e o número de docentes em cursos de pós-graduação (mestrado e doutorado) no país, como pode ser observado por meio da tabela 1. Tal avanço pode ser creditado ao forte aumento no número de instituiçóes de ensino superior no país, assim como ao aumento no número de mestres e doutores. Indicadores como o número de bolsas de estudos para formação no exterior também apresentaram expansão no decorrer da década. Desta forma, a esfera científica do SNI brasileiro avançou tendo como principal resultado desse processo o aumento na produção de artigos científicos publicados em periódicos internacionais, como pode ser visto também por meio da figura 3. 
TABELA I | Evoluçáo do SNI brasileiro: 2000 - 2010

\begin{tabular}{|l|r|r|c|}
\cline { 2 - 4 } \multicolumn{1}{c|}{} & $\mathbf{2 0 0 0}$ & $\mathbf{2 0 1 0}$ & $\begin{array}{c}\text { CRESCIMENTO } \\
(\%)\end{array}$ \\
\hline Patentes & 7.259 & 8.582 & 18,2 \\
\hline Artigos científicos & 5.095 & 29.958 & 488,0 \\
\hline Docentes de pós-graduação & 29.190 & 60.038 & 105,7 \\
\hline Microrregióes com patentes & 253 & 285 & 12,6 \\
\hline Microrregióes com artigos científicos & 175 & 355 & 102,9 \\
\hline Microrregióes com cursos de pós-graduação & 68 & 115 & 69,1 \\
\hline
\end{tabular}

FONTE ELABORAÇÃo PRÓPRIA A PARTIR DE ISI, INPI E GEOCAPES

Todavia, é observável que a produção tecnológica, ilustrada pelo número de pedidos de patentes no período, não apresentou o mesmo vigor em seu crescimento que o verificado para as atividades científica e de formação profissional. É possível deduzir, a partir desse cenário, que o avanço no SNI brasileiro foi baseado nas esferas científica e de ensino, fortemente ligadas ao setor público no Brasil. Já a esfera tecnológica, que refletiria o esforço dos setores produtivos, apresentou um ritmo de crescimento menos empolgante.

Outro aspecto relevante, no que tange à tabela 1 e à figura 3, diz respeito ao ganho de abrangência regional do SNi brasileiro, entre os anos de 2000 e 2010. Observa-se que o número de microrregióes com registros de patentes, docentes de pós-graduação e, especialmente, artigos aumentou ao longo do período. Nesse sentido, é possível considerar que o avanço do sNI brasileiro foi acompanhado de um processo de redistribuição espacial de seus atores, fazendo com que um número maior de microrregióes passasse a contar com a presença de seus entes. Novamente cabe destaque à produção científica, uma vez que para 2010 o número de localidades que apresentaram tal atividade foi o dobro do observado em 2000.

A figura 3 ilustra a distribuiçấo da atividade científica entre as microrregiōes brasileiras, mostrando que, embora também exista concentração regional para tal indicador, é possível identificar uma maior participação de localidades fora do eixo sul-sudeste, em oposição ao observado para o indicador de patentes. Esse resultado reflete o foco da política de expansão do sistema de ensino superior no Brasil, especialmente o público, contemplando localidades menos desenvolvidas e fora do circuito econômico mais dinâmico. Nesse sentido, a comparação envolvendo os anos de 2000 e 2010 indica uma melhor distribuição espacial da produção científica no território brasileiro para o ano mais recente.

De forma similar, e pautada no mesmo processo, o número de microrregióes com cursos de pós-graduação também apresentou considerável crescimento ao longo do período observado. Já a atividade tecnológica apresentou menor ritmo de expansão territorial. Esse dado pode indicar que a expansão no sistema de ensino e na produção científica ainda não geraram os devidos transbordamentos sobre a atividade tecnológica ou que as esferas produtivas não reuniram, ainda, condiçóes de absorver possíveis ganhos oriundos do aumento na produção científica brasileira. 
FIGURA 3 | Distribuição da produção de artigos científicos por milhão de habitantes por microrregióes brasileiras - $2000-2010$
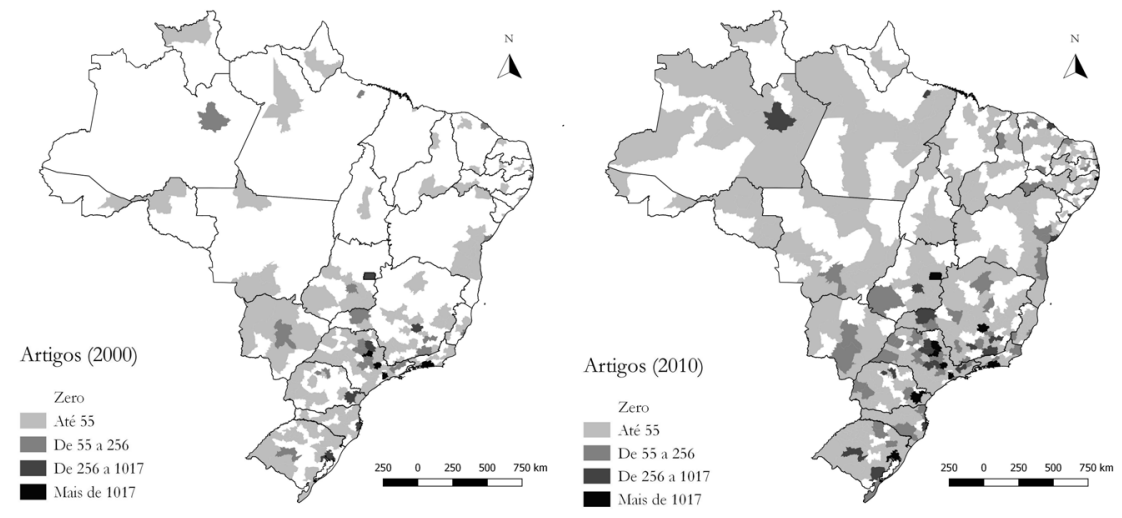

FONTE ELABORAÇÃO PRÓPRIA A PARTIR DE DADOS DO ISI WEB OF SCIENCE

Cabe considerar que mesmo com o processo recente de ampliação do SNI, o país em pouco avança no que tange à distância em relação aos SNIs de países mais desenvolvidos. Observa-se que o ritmo de crescimento das produçóes científica e tecnológica brasileiras necessita ser ampliado para que se possa, de fato, alcançar os países mais avançados econômica e tecnologicamente (Ribeiro, Ruiz, Bernardes, \& Albuquerque, 2006). Acredita-se que tal incremento no SNI brasileiro deve ser orientado pela continuidade de sua redistribuição territorial. Deste modo, a consolidação do SNI brasileiro deve ser orientada pelo desenvolvimento de estruturas de CT\&I especialmente em regióes mais pobres e fora do eixo territorial mais dinâmico, em termos industriais. Fazendo, assim, que o sistema brasileiro de inovação apresente maior grau de continuidade espacial.

\section{Aspectos metodológicos}

\section{Base de dados}

A base de dados para a análise empírica foi construída na forma de um painel balanceado, contendo informaçóes dos anos de 2000 e 2010 para todas as 558 microrregiôes do Brasil, totalizando 1116 observaçóes.

Para avaliar os efeitos dos atores regionais do sistema nacional de inovação sobre as atividades de serviços e o setor industrial foi utilizada como variável o Índice de Desenvolvimento Regional do Sistema de Inovação (IDRSI). Esse índice foi desenvolvido por Santos (2014) com vistas a identificar as mudanças na distribuição regional dos entes do SNI brasileiro entre 2000 e 2010. Trata-se de um indicador obtido por meio do método de análise fatorial a partir de três variáveis que abrangem as atividades científica, tecnológica e de qualificação profissional no âmbito do SNI. Tais variáveis são o número de artigos científicos publicados por milhão de habitantes, o número de patentes por milhão de habitantes e o número de docentes de pós-graduação por milhão de habitantes para cada microrregião 
brasileira. O número de artigos científicos foi obtido a partir de pesquisa junto ao sitio do Institute of Science Information (ISI Web of Science), do qual foram identificados os artigos publicados por residentes no Brasil em periódicos indexados pela instituição para os anos de 2000 e 2010 . O número de artigos científicos é recorrentemente utilizado como proxy para a produção científica pela literatura acerca dos sistemas de inovação (Albuquerque, 1999). O número de depósitos de patentes por microrregiáo é oriundo de uma tabulação especial fornecida pelo Instituto Nacional de Propriedade Industrial (INPI). Dados de patentes, por sua vez, configuram a principal proxy para a produção tecnológica (Jaffe, 1989). Por fim, o número de docentes de pós-graduação foi obtido perante consulta junto à base de dados do portal GeoCapes. Estes dados foram ponderados pelas populaçôes microrregionais disponibilizadas pelo portal Ipeadata.

O modelo de análise fatorial, utilizado para a criação do IDRSI a partir das variáveis acima descritas, leva a uma redução da dimensionalidade conjunto original de variáveis num número menor de fatores que resumiriam suas informaçôes originais (Mingoti, 2005) . Uma vez obtidos os fatores, é possível calcular seus valores numéricos para cada elemento amostral. Cada um desses valores $\mathrm{Fi}$, denominado escore do fator $\mathrm{i}$, resume o conjunto de informaçóes refletidas pelas variáveis originais de análise padronizadas, para cada observação i, conforme a equação abaixo.

$$
\mathrm{Fi}=\mathrm{c} 1 \mathrm{iZi}+\mathrm{c} 2 \mathrm{iZi}+\mathrm{c} 3 \mathrm{iZi}
$$

Os valores do IDRSI são obtidos, portanto, pelos escores $\mathrm{F}$ referentes a cada uma das microrregiôes observadas. Nesse sentido, o índice proposto é uma combinação linear das variáveis acima apontas, a qual sumarizaria suas variáveis em um único indicador. O IDRSI, é definido, entâo, pelos escores do primeiro fator obtido ao se aplicar o método de análise fatorial para os períodos de 2000 e 2010 aos dados referentes ao SNI brasileiro em suas 558 microrregióes, como definido pela equação abaixo:

IDRSIi $=$ c1i $($ Patentes $/$ milhão de hab i $)+$ c2i(Artigos $/$ milhão de habi $)+$ c3i $($ Docentes de pós/milhão de habi)

Os coeficientes cji são os pesos para a ponderação das variáveis utilizadas na composiçáo do IDRSI, sendo estimados pelo método dos mínimos quadrados ordinários, com base na matriz de loadings, que representam a correlação entre as variáveis originais e os fatores oriundos da análise fatorial (Mingoti, 2005). Disso, conclui-se que o IDRSI consiste numa soma ponderada dos valores das três variáveis originais utilizadas em sua construção, para cada microrregião, sendo os fatores de ponderação os coeficientes que expressam o relacionamento do fator com a variável a que se refere (Santos, 2014). Logo, quanto maior for o valor para o IDRSI, maior será a participação de atores do SNI na microrregião considerada. Cabe considerar que os scores para os fatores obtidos por análise fatorial são padronizados, de modo a apresentar média igual a 0 e desvio padrão igual a 1 .

O principal propósito do trabalho é identificar como o IDRSI afeta o desempenho da atividade industrial e do setor de serviços em uma perspectiva regional, com 
vistas a avaliar os possíveis efeitos do processo de expansão territorial do SNI brasileiro sobre as atividades econômicas ao longo de suas microrregióes. Cabe destacar que entre 2000 e 2010 foi identificado num crescimento superior a $40 \%$ no total de microrregióes brasileiras com IDRSI superiores à média nacional, indicando uma maior abrangência territorial do SNI brasileiro. Destaca-se que para a análise proposta outras variáveis de controle foram utilizadas para o desenvolvimento do exercício empírico proposto.

Parte dos dados utilizados foi extraída do IBGE (PIB, PIB industrial e PIB serviços). Os dados, municipais, foram agrupados por microrregião e ponderados pela populaçáo. Outra transformação feita nos dados foi a construçáo de variáveis de ponderação espacial. A ideia da construção destas variáveis está fundamentada na tentativa de tratamento econométrico para as possíveis influências territoriais, características do objeto de análise. Entende-se que ao avaliar os fatores que determinam o desempenho industrial e do setor de serviços é importante levar em consideração possíveis influências do entorno. ${ }^{1}$ A variável de exportaçóes foi obtida no AliceWeb/MDIC. O mesmo tratamento de agrupar em microrregióes, relativizar pela populaçáo e ponderar pela possível influência do entorno foi feita para esta variável. Importante destacar a inexistência de dados (municipalizados) de exportaçóes para o ano de 2000. A alternativa adotada foi utilizar os dados de 2003 como proxy. ${ }^{2}$

\section{Metodologia}

O propósito do trabalho de identificar como a variável IDRSI determina o desempenho industrial e do setor de serviços esbarra na tentativa de encontrar uma especificação econométrica que minimize erros de omissão de variáveis explicativas e que permita o avanço nos tratamentos metodológicos necessários à identificaçáo do modelo.

Partindo de uma primeira especificação de análise da causalidade de IDRSI em PIB (industrial) е рів (serviços), tem-se:

\section{$\mathrm{Y}_{\text {industrial }}=\alpha+\beta^{*} \operatorname{IDRSI}+\varepsilon$}

$$
\mathrm{Y}_{\text {serviços }}=\alpha+\beta * \text { IDRSI }+\varepsilon
$$

Assume-se que nessa primeira especificação o modelo passa a ter problemas de viés de omissão de variável relevante, que seriam capturadas nos termos de erro e tornariam os ß não confiáveis.

Outras variáveis de controle foram incluídas nas estimaçôes, na tentativa de avançar na identificação do melhor modelo. Para os determinantes do desempenho industrial são incluídas variáveis de exportaçóes (per capta), dummy para o ano de 2010. Para os determinantes do desempenho do setor de serviços é incluída, além das duas variáveis citadas acima, uma variável de PIB industrial, buscando identificar se o setor de serviços tem sua dinâmica afetada pelo setor industrial. Também

1 Este aspecto será mais bem abordado na descrição da metodologia.

2 O ano de 2003 foi o primeiro que houve disponibilização de dados municipais de exportaçôes. 
são incluídas dummies referentes à macrorregião (Norte, Nordeste, Centro Oeste, Sudeste e Sul) em que se encontra a microrregião em questáo, na tentativa de controlar os efeitos da grande heterogeneidade da distribuição da atividade produtiva no Brasil (seja industrial ou de serviços).

Como a unidade de análise é territorial, entende-se que o uso de econometria espacial auxilia a identificação do modelo (Almeida, 2012). Neste sentido, a busca por indicadores territoriais que possam capturar a influência exercida pela proximidade passa a ser foco da análise. Ignorar esta dependência espacial na especificação do modelo tende a violar pressupostos do modelo clássico de regressão linear, o que pode a acarretar ineficiência e viés nos estimadores, mesmo com grandes amostras.

Além da acomodação da dependência espacial no modelo, outra possibilidade de avanço metodológico está no uso do painel de dados, que além de fornecer maior número de observaçôes permite uma maior acomodação da heterogeneidade dos dados, com possível eliminação (ou tratamento) de características particulares da unidade de análise durante a estimação.

Determinantes do PIB - serviços

A identificação do modelo dos determinantes do PIB de serviços ), usando um painel de dados espaciais, segue a estrutura abaixo:

$\mathrm{Y}_{\text {serviços it }}=\alpha+\beta_{1} * \operatorname{IDRSI}_{\mathrm{it}}+\beta_{2} * \mathrm{Y}_{\text {industrial it }}+\beta_{3} *$ Export $_{\mathrm{it}}+\beta_{4} *$ dummy2010 $_{\text {it }}+\beta_{5} *$ $\mathrm{W}_{-} \mathrm{PIB}+\beta_{6} * \mathrm{~W}_{-}$Export $_{\text {it }}+\beta_{7} * \mathrm{~W}_{-} \mathrm{Y}_{\text {industrial it }}+\varepsilon_{\text {it }}$

Com о PIB de serviços sendo determinado por IDRSI, PIB industrial, capacidade exportadora, e influenciado pela dinâmica econômica das regiôes vizinhas (W_PIB), pela dinâmica exportadora das regiốes vizinhas (W_Export) e pela dinâmica industrial das regióes vizinhas ( $\mathrm{W}_{-} \mathrm{Y}_{\text {industrial }}$ ). Neste caso, o termo de erro assume a $\boldsymbol{\varepsilon}_{\text {it }}$ seguinte especificação:

$$
\varepsilon_{\mathrm{it}}=\mu_{\mathrm{i}}+\mathrm{v}_{\mathrm{it}}
$$

Dentro das possibilidades do uso dos dados em painel, o modelo de efeito fixo assume que o termo de erro não observado $\left(\mu_{i}\right)$ é fixo para cada unidade de observação e o outro componente do termo de erro ${ }^{\left(v_{i t}\right)}$ é IID (com média 0 e variância $\sigma^{2}$ ). Para os modelos de efeitos aleatórios, o erro não observado $\mu_{i}$ é assumido alea- tório $\mathrm{e}$ IID $\left[\mu_{i} \sim \operatorname{iid}\left(0, \sigma^{2}\right)\right]$, assim como o erro $v_{i . t}$, sendo ainda $\operatorname{corr}\left(u_{i}, v_{i t}=0\right)$ e $\operatorname{corr}\left(x_{i t}, u_{i}, v_{i t}=0\right)$

\section{Determinantes do PIB - industrial}

Para os determinantes do PIB industrial $\left(\mathrm{Y}_{\text {industrial }}\right)$, usando um painel de dados espaciais, tem-se:

$$
\begin{aligned}
& \mathrm{Y}_{\text {industrial it }}= \\
& \alpha+\beta_{1} * \mathrm{IDRSI}_{\mathrm{it}}+\beta_{2} * \text { Export }_{\text {it }}+\beta_{3} * \text { dummy2010 }_{\text {it }}+\beta_{4} * \mathrm{~W}_{-} \mathrm{PIB}+\beta_{5} * \mathrm{~W}_{-} \text {Export }_{\text {it }}+\beta_{6} * \\
& \mathrm{~W}_{-} \mathrm{Y}_{\text {industrial it }}+\varepsilon_{\mathrm{it}}
\end{aligned}
$$


$\mathrm{Na}$ identificação dos determinantes da dinâmica industrial é preciso esclarecer que a variável da dinâmica industrial das regióes vizinhas $\mathrm{W}_{-} \mathrm{Y}_{\text {industrial }}$ ) utilizada no modelo não pode ser a variável observada (Almeida, 2012). Caso fosse esta, existiria um viés de simultaneidade nesta determinação (a microrregião influencia seus vizinhos e também é influenciada por eles). A estratégia econométrica foi utilizar o W_Y industrial estimado como instrumento para o $\mathrm{W}_{-} \mathrm{Y}_{\text {industrial }}$ observado, fazendo a estimação em dois estágios (em uma primeira etapa estimou-se a ponderação espa$\mathrm{cial}^{3}$, para em uma segunda etapa utilizar esta variável como explicativa). Nesta especificação, a identificação do modelo assume as mesmas características descritas para o modelo anterior (determinação da dinâmica do setor de serviços), no que diz respeito ao termo de erro.

TABEla 2 Descrição das variáveis utilizadas na análise empírica

\begin{tabular}{|c|c|c|c|c|c|}
\hline VARIÁVEIS & DESCRIÇÃO & $\begin{array}{l}\text { UNIDADE } \\
\text { DE } \\
\text { MEDIDA }\end{array}$ & MÉDIA & MÍNIMO & MÁXIMO \\
\hline \multicolumn{6}{|c|}{ Variáveis contínuas } \\
\hline IDRSI & $\begin{array}{l}\text { Índice de Desenvolvimento Regional no } \\
\text { Sistema de Inovaçâo }\end{array}$ & contínua & $1,14 \mathrm{E}-07$ & $-0,3060$ & 15,2372 \\
\hline $\begin{array}{l}\text { PIB industrial } \\
\text { (per capta) }\end{array}$ & $\begin{array}{l}\text { Produção industrial por habitantes da } \\
\text { microrregiâo (a preços de 2000) - IBGE }\end{array}$ & $\mathrm{R} \$ 1.000,00$ & 1,93 & 0,06 & 26,43 \\
\hline $\begin{array}{l}\text { PIB serviços } \\
\text { (per capta) }\end{array}$ & $\begin{array}{l}\text { Produçáo do setor de serviços por } \\
\text { habitantes da microrregiāo (a preços de } \\
\text { 2000) - IBGE }\end{array}$ & $\mathrm{R} \$ 1.000,00$ & 2,83 & 0,55 & 21,31 \\
\hline $\begin{array}{l}\text { Exportaçóes } \\
(\text { per capta) })\end{array}$ & $\begin{array}{l}\text { Exportaçóes por habitantes da microrre- } \\
\text { giāo (FOB) - MDIC }\end{array}$ & US\$ 1.00 & 643,83 & 0,00 & 46989,31 \\
\hline $\begin{array}{l}\text { PIB (per capta) } \\
\text { vizinhos }\end{array}$ & $\begin{array}{l}\text { Ponderação espacial do PIB das microrre- } \\
\text { giōes vizinhas (a preço de 2000) - IBGE }\end{array}$ & $\mathrm{R} \$ 1.000,00$ & 5,34 & 1,32 & 17,05 \\
\hline $\begin{array}{l}\text { Exportaçóes } \\
\text { (per capta) } \\
\text { vizinhos }\end{array}$ & $\begin{array}{l}\text { Ponderação espacial das exportaçóes das } \\
\text { microrregiốes vizinhas (FOB) - MDIC }\end{array}$ & US\$ 1.00 & 610,73 & 0,00 & 16354,67 \\
\hline $\begin{array}{l}\text { PIB industrial } \\
\text { (per capta) } \\
\text { vizinhos }\end{array}$ & $\begin{array}{l}\text { Ponderação espacial do PIB industrial } \\
\text { das microrregiôes vizinhas (a preço de } \\
\text { 2000) - IBGE }\end{array}$ & $\mathrm{R} \$ 1.000,00$ & 1,31 & 0,10 & 8,64 \\
\hline \multicolumn{6}{|c|}{ Variáveis categóricas } \\
\hline Norte & $\begin{array}{l}\text { Dummy para microrregiáo localizada na } \\
\text { regiáo norte }\end{array}$ & binária & 0,1147 & 0 & 1 \\
\hline Nordeste & $\begin{array}{l}\text { Dummy para microrregiáo localizada na } \\
\text { regiâo nordeste }\end{array}$ & binária & 0,3369 & 0 & 1 \\
\hline Centro-Oeste & $\begin{array}{l}\text { Dummy para microrregiâo localizada na } \\
\text { regiấo centro-oeste }\end{array}$ & binária & 0,0932 & 0 & 1 \\
\hline Sudeste & $\begin{array}{l}\text { Dummy para microrregiấo localizada na } \\
\text { regiấo sudeste }\end{array}$ & binária & 0,2867 & 0 & 1 \\
\hline Sul & $\begin{array}{l}\text { Dummy para microrregiấo localizada na } \\
\text { regiâo sul }\end{array}$ & binária & 0,1685 & 0 & 1 \\
\hline
\end{tabular}

FONTE ELABORAÇÃO PRÓPRIA COM BASE EM IBGE, MDIC, ISI, INPI E GEOCAPES

3

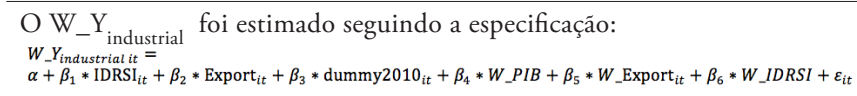


A matriz de ponderação espacial (W) utilizada nos exercícios empíricos foi a "RAINHA", que é uma matriz de proximidade geográfica de contiguidade. Isso significa que a análise econométrica levou em consideração que todos os vizinhos limítrofes às microrregiōes exercem influência na dinâmica microrregional e, para tanto, foi feito o devido controle.

A tabela 2 descreve as variáveis utilizadas nos exercícios empíricos e a tabela 3 apresenta a matriz de correlação das variáveis. Observa-se que a variável IDRSI, como esperado apresenta correlação positiva com as variáveis relativas ao nível de atividade econômica. Contudo, tais correlaçôes são relativamente baixas. Tal resultado pode ser um indicativo da já recorrentemente observada baixa conexão entre os atores do SNI brasileiro, especialmente os ligados ao ensino e à pesquisa, e a estrutura produtiva do país (Albuquerque, 1999). 


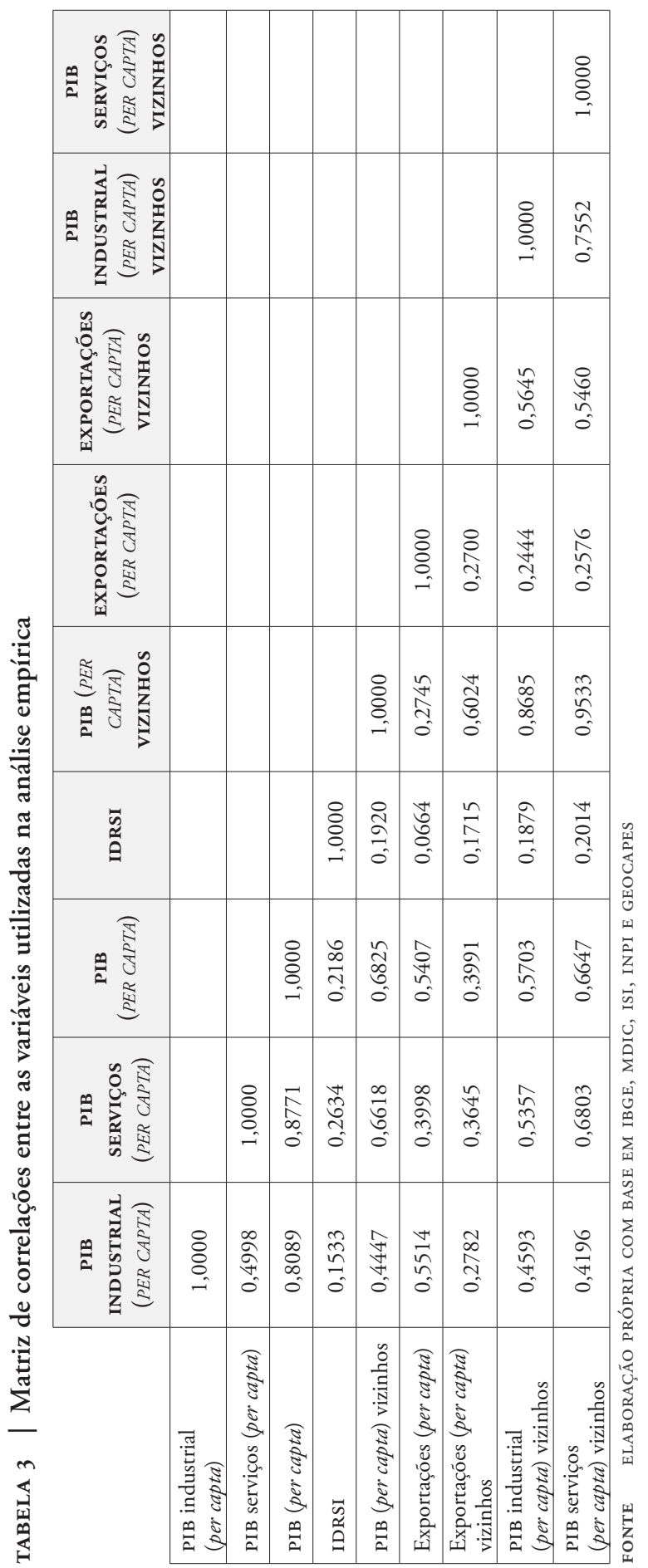




\section{Análise dos resultados}

A análise dos resultados será feita com base nas tabelas 4 e 5, que seguem. O foco da análise diz respeito a identificar a relação entre a variável IDRSI e o nível de atividade dos setores indústria e serviços para as microrregióes brasileiras. Com isso, pretendese avaliar como os avanços na distribuiçấo espacial recente do SNi brasileiro podem ter impactado em atividades econômicas regionais. Para tal, a tabela 4 apresenta os resultados da estimação dos determinantes do setor de serviços enquanto a tabela 5 apresenta os resultados da estimação dos determinantes da dinâmica industrial.

Como descrito na parte metodológica, para os dois exercícios foram feitas algumas tentativas de identificar o melhor modelo a ser estimado, representadas nas cinco especificaçóes de MQO. Posteriormente foi feito o uso do instrumental de painel, com estimação de Efeitos Fixos e Efeitos Aleatórios. Para os dois casos foram feitos o teste de Hausman, que identificou qual é o modelo preferido.

Ainda antes de entrar na análise dos resultados dos modelos finais, cabe salientar que a primeira especificação proposta, que apenas tentava mensurar a influência exercida por IDRSI em PIB de serviços e PIB industrial, obteve o resultado previamente esperado. Com um efeito positivo e bastante significativo, indicando que o IDRSI reforça substancialmente a dinâmica destes dois setores. Em outras palavras, a presença de atores do SNI nas microrregióes geraria efeitos positivos tantos em suas atividades no setor serviços quanto em suas atividades no setor industrial. Entretanto, como já apresentado na metodologia, esta primeira especificação apresenta problemas de omissão de variáveis relevantes, enviesando os resultados.

A interpretação dos resultados da estimação dos determinantes da dinâmica do setor de serviços será feita com base nos resultados do modelo de Efeitos Fixos. O teste de Hausman ${ }^{4}$ indicou que este modelo é preferível em relação ao de efeitos aleatórios.

A primeira constatação a ser feita, com base na análise da variável de maior interesse, diz respeito ao fato de a variável IDRSI não ser estatisticamente significante, apesar de ter um efeito positivo, como se esperava a priori. Interessante notar que em todas as demais especificaçóes esta variável teve um efeito positivo e significativo, indicando que ela reforça a dinâmica deste setor. A interpretaçáo para a perda de significância pode estar relacionada à eliminação de características regionais (invariantes no tempo) que acabaram "extraindo" poder explicativo da variável IDRSI. Antes dessa eliminação tais características estariam presentes no termo de erro e, sem este correto tratamento, o IDRSI apresentava uma significância que seria oriunda de uma variável omitida. O mesmo ocorre com a variável pIB industrial, da qual seria esperado um sinal positivo, de reforço na dinâmica do setor de serviços, mas que não é estatisticamente significativo (assim como em IDRSI, em todas as demais especificaçóes o efeito foi positivo e significativo). 


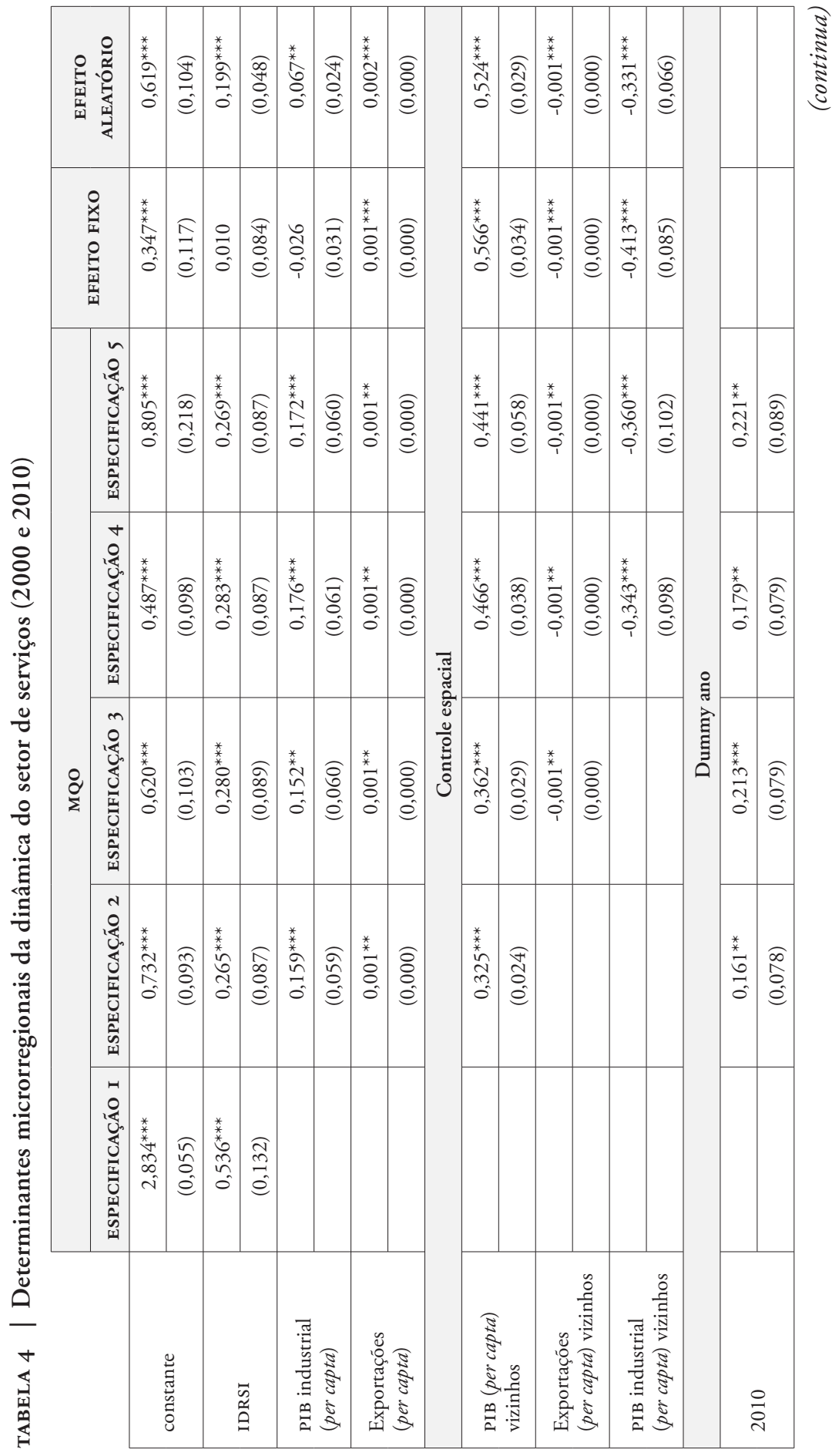




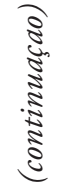

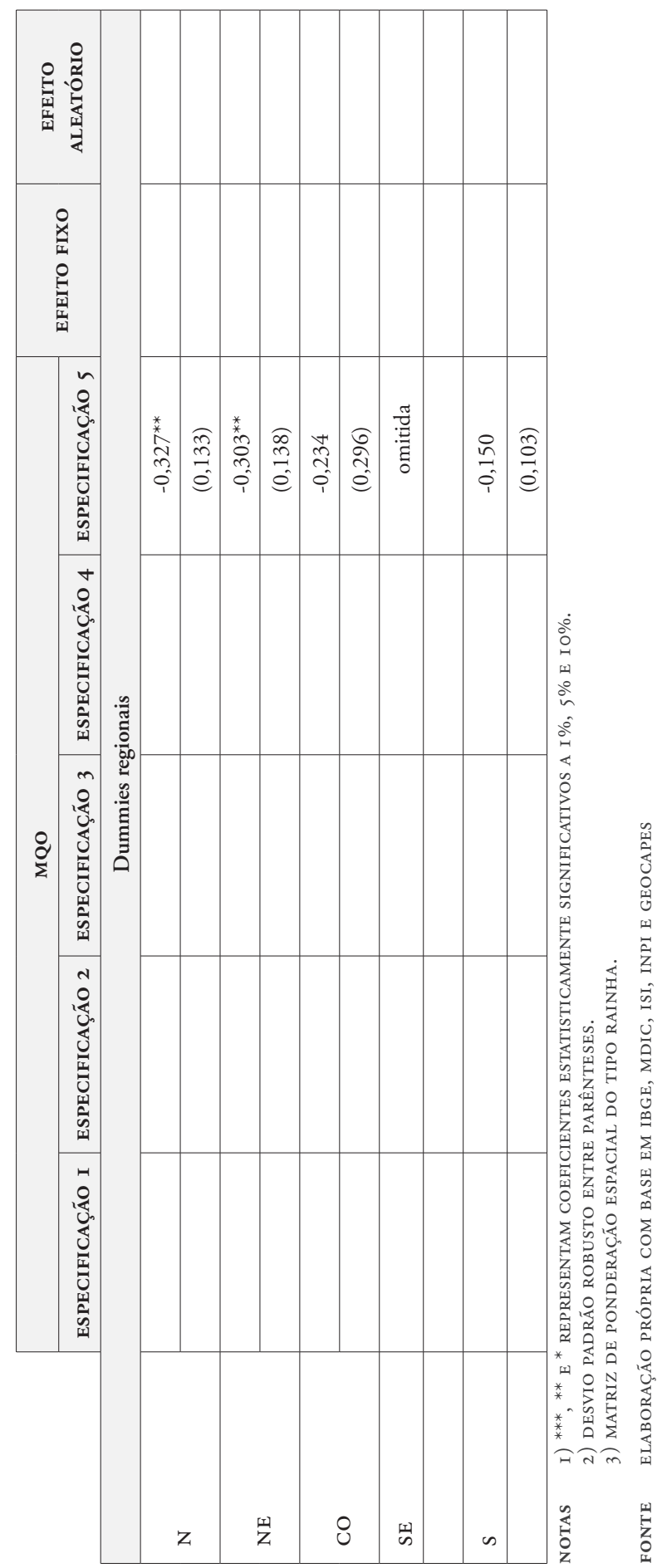


Deve-se considerar que o setor serviços apresenta grande abrangência, englobando um vasto número de atividades, sendo muitas delas caracterizadas pela baixa intensidade tecnológica e restrita produtividade. Nesse sentido, acredita-se que o peso dos serviços de menor produtividade possa contribuir para fato de não ter sido alcançada significância estatística para o IDRSI no modelo acima apresentado. $\mathrm{Ou}$ seja, para boa parte das atividades de serviços, a presença local de atores do SNI não resultaria em melhoras diretas para a sua dinâmica. Acredita-se que uma nova especificação da variável dependente, considerando prioritariamente o produto de segmentos do setor serviços com maior grau de produtividade poderia contribuir para que os resultados fossem mais próximos ao que se pressupóe a priori quanto aos efeitos do IDRSI sobre essa atividade.

Destaca-se, ainda, que a dinâmica do setor exportador afeta positivamente o setor de serviços, mas em uma magnitude muito baixa (apesar de muito significativo, estatisticamente). Ainda em relação ao setor exportador, resultado, também, interessante se refere ao fato de a dinâmica exportadora das regióes vizinhas afetar negativamente a dinâmica dos serviços na região em análise. Isso pode significar que o setor exportador geraria maiores efeitos sobre a dinâmica econômica interna à região em que se localiza, estando entre esses resultados uma capacidade de atração de atividades de serviços localizadas em microrregióes vizinhas. Isso explicaria seus efeitos positivos sobre os serviços localizados internamente à região considerada, e os efeitos positivos gerados sobre a dinâmica dos serviços em regióes vizinhas.

$\mathrm{O}$ resultado da influência do рIв das regióes vizinhas sobre o setor de serviços indica sinal e significância esperados. Ou seja, a dinâmica econômica (geral) do entorno induz o setor de serviços nas microrregiôes consideradas. Esse dado indica que os serviços apresentam encadeamentos regionais. Já na análise do PIB industrial, a lógica se assemelha ao setor exportador, ou seja, o dinamismo industrial das regióes vizinhas afeta negativamente o setor de serviços (dentro da microrregiáo). A explicação, assim como na análise do setor exportador, poderia estar relacionada à maior capacidade de geração de dinâmica do setor industrial no setor de serviços internamente à região em que este se localiza (entretanto isto não se confirmou na análise específica desta variável, que não foi estatisticamente diferente de zero).

Nos modelos em que houve a inclusão de uma dummy para identificar diferenças entre os anos de 2000 e 2010 observou-se, em todos, que o ano de 2010 apresentou um maior dinamismo no setor de serviços (coeficiente positivo e estatisticamente significante). Nesse sentido, é possível considerar que houve uma melhora no que tange à dinâmica econômica do setor serviços nas microrregióes do país ao longo do período avaliado.

A tabela 5, a seguir, apresenta os resultados da análise dos determinantes microrregionais da dinâmica do setor industrial. O teste de Hausman, para esta análise, indicou que o modelo de Efeitos Aleatórios é preferível ao modelo de Efeitos Fixos. 


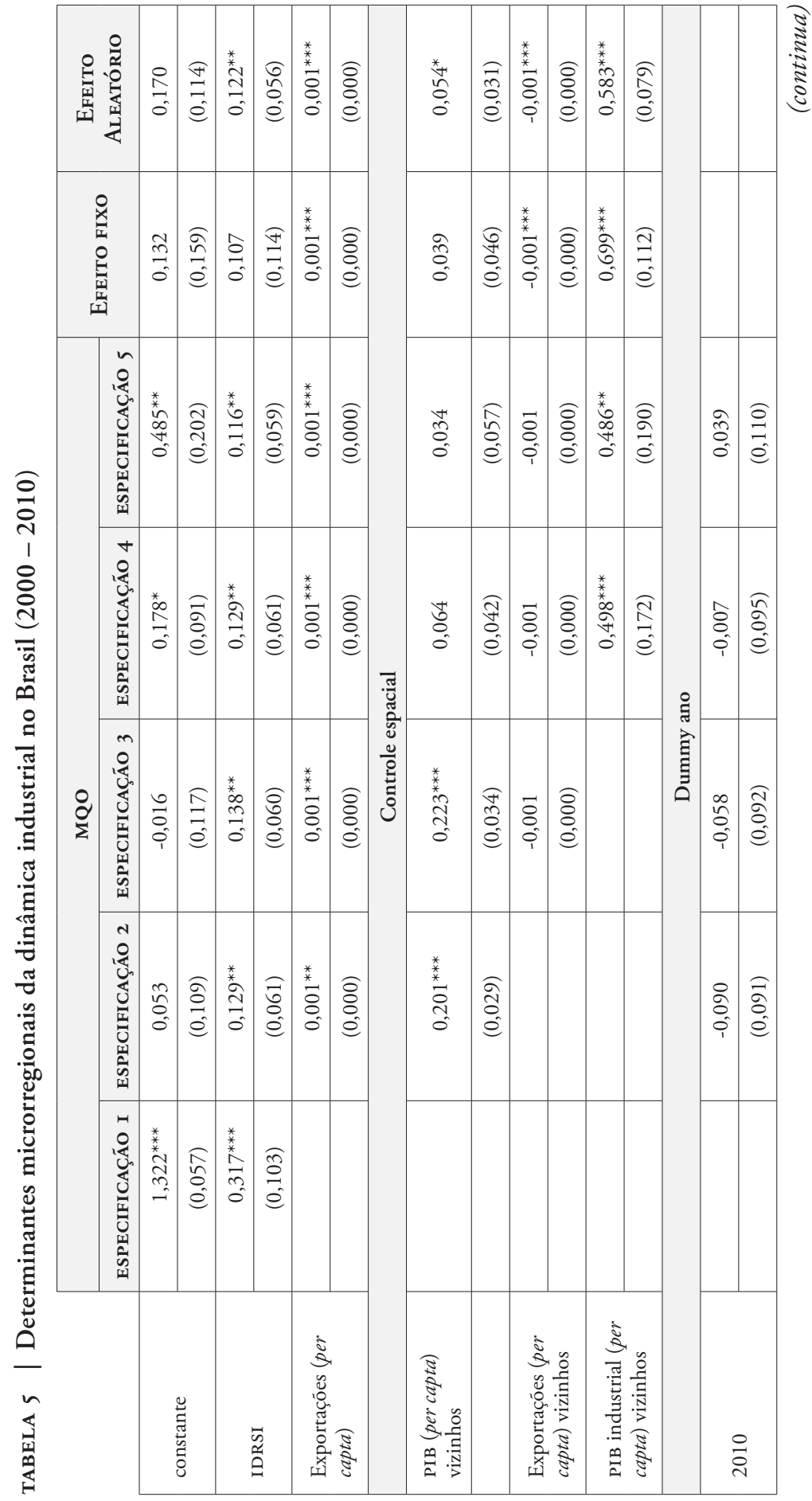




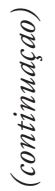

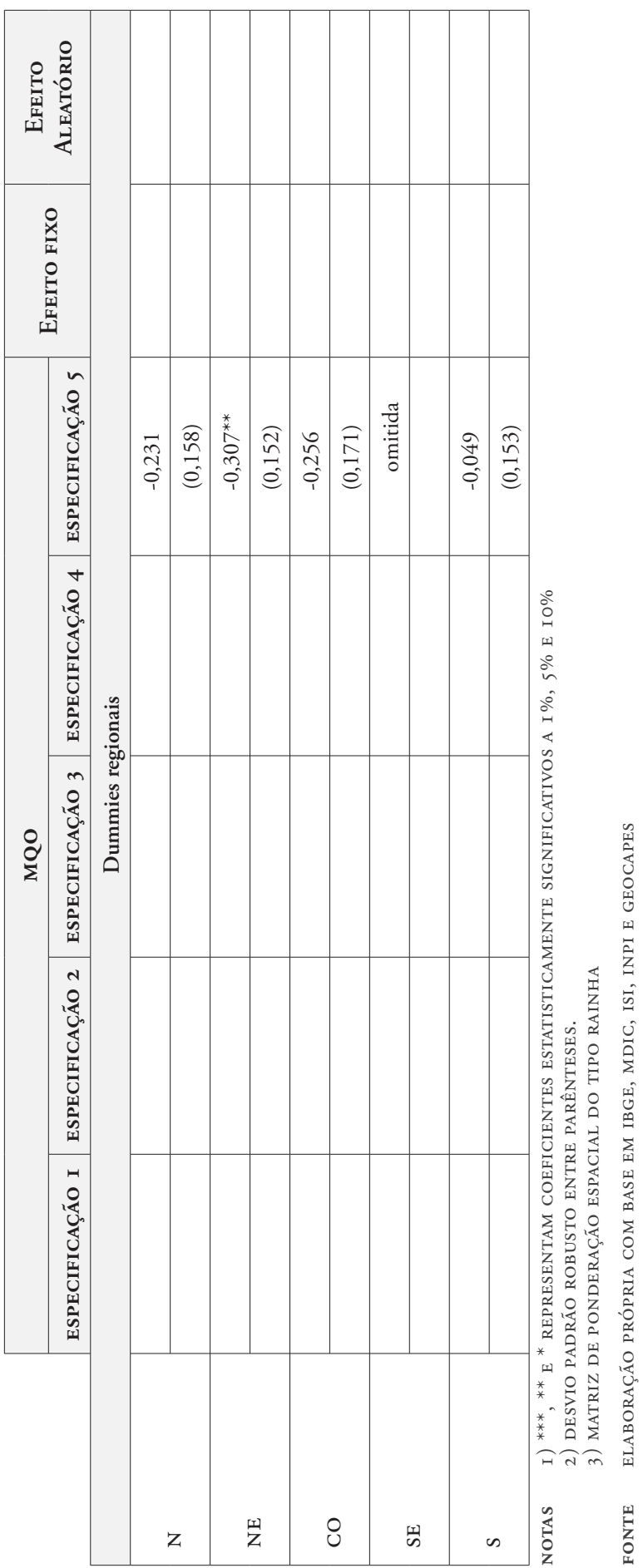


Para os determinantes da dinâmica industrial microrregional, a variável IDRSI apresenta o sinal esperado, positivo, e significativo estatisticamente, ou seja, ela atua em direção a reforçar a dinâmica industrial local. Esse resultado indica que a presença de atores do SNI influenciaria de forma positiva a atividade industrial nas microrregióes brasileiras. Trata-se de um resultado relevante, dado o processo recente de expansão do SNI brasileiro, o qual foi marcado pela busca de uma melhor distribuiçáo espacial de seus entes. Tal resultado também é condizente com a literatura, que sugere que a presença de instituiçóes de ciência e tecnologia geograficamente próximas seria um fator indutor da dinâmica econômica, e tecnológica, no setor industrial (Audretsch \& Feldman, 1996; Jaffe, 1989). Desta forma, é possível interpretar que a presença de atores do SNI brasileiro nas microrregióes desencadeia efeitos positivos sobre a indústria local, o que seria resultante das produçôes científica e tecnológica, bem como das atividades de formação e qualificação profissional inerentes à estrutura de sistemas de inovação. Sendo assim, a indústria colheria resultados positivos da proximidade junto a tais estruturas de ciência e tecnologia, sendo estes refletidos em sua maior produtividade, capacidade de inovação, e, consequentemente, maior geração de renda. Esse quadro reforça a importância do processo de redistribuição espacial dos entes dos SNI no país, dado que a atividade produtiva local colhe frutos de sua presença no mesmo ambiente regional.

No entanto, cabe observar que o IDRSI náo configurou o principal determinante da atividade industrial microrregional, de acordo com os dados avaliados. A variável referente à dinâmica industrial das microrregióes vizinhas foi a que apresentou o mais alto coeficiente entre as variáveis testadas no exercício empírico considerado, além de deter significância estatística. Esse resultado reflete a notória tendência da indústria em se beneficiar de spillovers resultantes da localização em aglomeraçóes produtivas (Asheim, 1996; Cooke, 1998). Nesse sentido, a existência de economias de aglomeração, referentes a aspectos como a infraestrutura local, a proximidade de clientes e fornecedores, a existência de oferta de trabalho qualificado e os fluxos de conhecimento proporcionados pela existência de indústrias no entorno, configuraria o principal determinante da indústria nas microrregióes observadas.

Destaca-se que o fato de as variáveis acima mencionadas serem as com coeficientes significativos mais importantes para a dinâmica microrregional do setor industrial é condizente com as expectativas orientadas pela literatura. Além disso, tais resultados indicam os caminhos para o desenvolvimento de políticas direcionadas ao setor industrial no país, as quais devem, portanto, contemplar a abrangência territorial do SNI, assim como as aglomeraçóes produtivas. Outro ponto a se destacar diz respeito à ordem de importância para as duas variáveis, que indicam que a dinâmica industrial do entorno teria maior impacto na dinâmica do setor do que a presença na microrregiáo de atores do SNI. Esse resultado pode sugerir que, perante a estrutura produtiva brasileira, as conexóes e encadeamentos inerentes a uma aglomeração produtiva seriam mais relevantes para a dinâmica do setor industrial que a existência de uma estrutura local de ciência e tecnologia. Trata-se, portanto, de um resultado que pode estar ligado ao padrão estrutural da indústria brasileira, marcado pela forte presença de setores de média-baixa e baixa densidades tecnológicas. Para tais setores a perspectiva de inovação tecnológica tende a ser baixa, o que leva a menores 
interaçôes para com os entes do SNI, se comparados aos setores com maior densidade tecnológica. No entanto, as relaçóes para com clientes e fornecedores fazem com que estes setores tenham fortes conexóes com outras indústrias.

Ainda sobre os resultados da estimação, tem-se que o setor exportador também afeta positivamente a dinâmica industrial, apesar de manifestar uma magnitude muito baixa de impacto. A pequena influência desta variável para a dinâmica industrial, observada no exercício empírico considerado pode estar relacionada à reduçáo da importância do setor industrial na composição das exportaçóes brasileiras ao longo do período considerado. Em relação a isso, deve-se considerar, ainda, a perda de competitividade da indústria de transformaçáo brasileira no mercado internacional frente a um processo de apreciação do câmbio real (Oreiro \& Feijó, 2010). Com isso, é possível entender as razóes pelas quais o mercado externo influenciou apenas levemente a dinâmica da indústria local, considerando o período 2000 - 2010. Ressalta-se, também, que, mantendo a ideia de que o setor exportador tenderia a reforçar apenas a dinâmica interna à regiáo, em detrimento de afetar seu entorno, o dinamismo do setor exportador do entorno tende a afetar negativamente a dinâmica industrial interna à microrregião, como observado pela estimaçáo de efeitos aleatórios.

O dinamismo econômico (geral) das microrregióes vizinhas também tende a afetar positivamente a dinâmica industrial interna, isso indica que a indústria se beneficia transbordamentos positivos do crescimento econômico de regióes próximas à sua localização. Logo, é perceptível que o setor industrial guarda relaçóes com a trajetória econômica de seu entorno sob vários aspectos. Considerando o PIB per capita do entorno das microrregióes avaliadas nessa análise, é possível observar a presença de encadeamentos regionais, não diretamente ligados à indústria, que favorecem o crescimento do setor numa dada localidade.

Deve-se destacar, por fim, que nas estimaçóes de MQO, em quatro especificaçóes em que foram incluídas as dummies de controle para diferenças entre os anos de 2000 e 2010 os resultados foram opostos à expectativa baseada na evoluçáo para o IDRSI no período. Em todas elas os resultados obtidos mostraram não haver diferenças (estatisticamente significativas) entre os dois anos para o PIB do setor indústria. Ou seja, não houve um aumento do dinamismo do setor industrial nas microrregióes consideradas ao longo da década. Esse resultado contrasta com os dados relativos ao IDRSI, dado que esse indicador apresentou forte aumento entre os anos de 2000 e 2010. Tal ausência de mudanças na dinâmica do setor industrial, considerando as especificaçóes do modelo em que foram inclusas dummies de ano, pode estar atrelada à redução do crescimento do setor na década de 2000, a qual tem sido atribuída a aspectos conjunturais como o movimento cambial do período (Oreiro \& Feijó, 2010). Desta forma, acredita-se que o baixo crescimento do setor possa estar relacionado a náo observaçáo de mudanças, estatisticamente significativas, na dinâmica da indústria entre os anos de 2000 e 2010, mesmo tendo o SNI brasileiro se expandido. 


\section{Consideraçóes finais}

O presente trabalho avaliou como atores do SNI influenciam a atividade econômica das microrregióes brasileiras. Parte-se da constatação que o SNI brasileiro passou por um processo de expansão ao longo do período entre 2000 e 2010, sendo essa marcada por um aumento da sua abrangência territorial. Com esse processo um número maior de microrregióes passou a contar com seus atores, especialmente com aqueles alinhados às atividades de ensino e pesquisa. Acredita-se que esse aspecto favorece o desenvolvimento regional, uma vez que a presença de atores do SNI pode induzir a atividade de inovação em uma determinada microrregião.

Esse aspecto foi parcialmente observado pelo presente trabalho, que fazendo uso de um painel de dados para os anos de 2000 e 2010, avaliou a dinâmica econômica dos setores indústria e serviços. Foi adotado um indicador, obtido por meio do método de análise fatorial, capaz de sumarizar informaçóes relativas ao grau de desenvolvimento dos atores que compóem o sNI localizado nas microrregióes brasileiras. Nesse sentido, exercícios econométricos foram realizados para verificar os efeitos deste indicador, ou seja, da presença de atores do SNI nas microrregióes, sobre as atividades econômicas locais.

Os resultados indicaram que para a indústria é estatisticamente observável uma relação positiva entre a presença na microrregião de atores do SNI e o desempenho do setor. Desta forma, é verificável a relevância da existência de uma estrutura de ciência e tecnologia local para a dinâmica das atividades industriais. Tal resultado confirma estudos anteriores sobre a relevância da proximidade geográfica entre a indústria e os entes do sistema de inovação e indica a importância do processo recente de expansão do sni brasileiro. Com isso, acredita-se que as microrregióes que ao longo do período avaliado passaram a contar com atores deste sistema em seu território passam a gozar, de acordo com os resultados, de melhores condiçóes para a indução do seu crescimento industrial. Nesse sentido, uma política de expansão do SNI, pautada na sua redistribuição regional, englobando microrregiôes mais pobres, pode ser um importante vetor para o desenvolvimento regional e para a redução das desigualdades regionais.

Ressalta-se aqui a importância do setor industrial como indutor da atividade econômica e do desenvolvimento, em razão de sua maior capacidade em gerar transbordamentos sobre outros segmentos. Desta forma, a identificação de uma relação positiva entre o fortalecimento regional (microrregional, nesta análise) de atores do SNI e o desempenho da indústria local traz luz à discussão de desenvolvimento regional no Brasil, dado o histórico de concentração da atividade produtiva no país (notadamente industrial). Tal resultado permite especular sobre as possibilidades de redistribuição espacial desse setor no Brasil, o que se coloca como importante objeto para pesquisas futuras, dado a trajetória recente do setor industrial no país.

Outro resultado relevante diz respeito ao peso da atividade industrial do entorno sobre o desempenho da indústria nas microrregióes avaliadas. Os dados indicam, inclusive, que a aglomeração produtiva teria maior importância sobre o desempenho do setor que a estrutura regional de C\&T. Essa condição estaria relacionada à baixa maturidade do SNi brasileiro, relacionada, sobretudo, à fragilidade das interaçóes 
entre a esfera industrial e a esfera científica. Trata-se também de uma característica da indústria do país, sustentada principalmente por setores de tecnologia madura e pouco dependentes da ciência para inovar.

Em relação ao setor serviços, observou-se a ausência de significância estatística do IDRSI para explicar a dinâmica do setor, embora o coeficiente observado sugira uma relação positiva. Acredita-se que o fato de o setor serviços contemplar um amplo conjunto de segmentos que não se beneficiariam diretamente da presença de atores do SNI, especialmente os serviços com menor produtividade, explicaria a inexistência de relação estatística entre o IDRSI e a dinâmica do setor para o exercício aqui realizado.

De uma forma geral, é possível concluir que a redistribuição espacial do SNI brasileiro, contemplando localidades que não contavam com seus atores, pode ser uma fonte de novas oportunidades para o desenvolvimento produtivo, sobretudo, para a indústria. Com isso, acredita-se que as políticas públicas visando ao desenvolvimento regional devem ser associadas às políticas científica e tecnológica, considerando que a localização dos atores do SNI tem importantes repercussóes para as atividades produtivas. Nesse sentido, é fundamental a continuidade do processo de expansão e redistribuiçáo espacial do sistema brasileiro de inovação, que ainda se encontra muito abaixo dos padróes observados para os países desenvolvidos.

\section{Referências bibliográficas}

Albuquerque, E. (1999). National systems of innovation and non-OECD countries: Notes about a rudimentary and tentative Typology. Brazilian Journal of Political Economy, 19(4), $35-54$.

Albuquerque, E., Simóes, R., Baessa, A., Campolina, B., \& Silva, L. (2002). A distribuição espacial da produção científica e tecnológica brasileira : uma descrição de estatísticas de produção local de patentes e artigos científicos. RBI-Revista Brasileira de Inovação, 1(2), 225-251. Disponível em http://www.ige.unicamp.br/ojs/index.php/rbi/article/ viewArticle/244

Almeida, E. (2012). Econometria Espacial Aplicada. Campinas: Alínea Editora.

Asheim, B. T. (1996). Industrial districts as "learning regions": a condition for prosperity. European Planning Studies, 4(4), 7-11. Disponível em http://www.tandfonline.com/ doi/abs/10.1080/09654319608720354

Asheim, B. T., \& Gertler, M. (2005). The geography of innovation. In J. Fagerberg, D. Mowery, \& R. R. Nelson (Eds.), The Oxford Handbook of Innovation (pp. 291-317). Oxford: Oxford University Press.

Audretsch, D., \& Feldman, M. (1996). R \& D spillovers and the geography of innovation and production. The American Ecnomic Review, 86(3), 630-641.

Cooke, P. (1992). Regional innovation systems: Competitive regulation in the new Europe. Geoforum, 23(3), 365-382. http://doi.org/10.1016/0016-7185(92)90048-9

Cooke, P. (1998). Introduction: origins of the concept. In H. Braczyc, P. Cooke, \& M. Hidernreich (Eds.), Regional Innovation Systems (pp. 2-25). London: UCL Press. 
Cooke, P. (2001). Regional Innovation Systems, Clusters, and the Knowledge Economy. Industrial and Corporate Change, 10(4), 44-45.

Doloreux, D. (2002). What we should know about regional systems of innovation. Technology in Society, 24(2), 243-263.

Edquist, C. (2005). Systems of innovation: perspectives and challenges. In J. Farceberg, D. Mowery, \& R. R. Nelson (Eds.), The Oxford Handbook of Innovation (pp. 181-208). Oxford: Oxford University Press.

Florida, R. (1995). Toward the Learning Region. Futures, 27(5), 527-536.

Freeman, C. (1987). Technology policy and economic performance. London: Pinter Publishers.

Freeman, C. (1995). The "National System of Innovation" in historical perspective. Cambridge Journal of Economics, 19, 5-24. Disponível em http://cje.oxfordjournals.org/ content/19/1/5.short

Freeman, C. (2002). Continental, national and sub-national innovation systems complementarity and economic growth. Research Policy, 31, 191-211.

Furtado, C. (1976). Formação Econômica do Brasil (14th ed.). São Paulo: Cia Editora Nacional.

Instituto Brasileiro de Geografia e Estatística (IBGE). (1990). Divisão Regional do Brasil em mesorregioes e microrregiöes geográficas (Vol. I). Rio de Janeiro: IBGE. http://doi. org/10.1017/CBO9781107415324.004

Isaksen, A. (2001). Building regional innovation systems: Is endogenous industrial development possible in the global economy? globalisation: A Challenge for local industrial policy regionalisation as an aspect of economic globalisation. Canadian Journal of Regional Science, 24(1), 101-120.

Jaffe, A. (1989). Real effects of academic research. American Economic Review, 79(5), 957-971.

Johnson, B. (1995). Institutional learning. In B.-A. Lundvall (Ed.), National Systems of Innovation: towards a theory of innovation and interactive learning (pp. 23-44). London: Pinter Publishers.

Lundvall, B.-A. (1995). Introduction. In B.-A. Lundvall (Ed.), National Systems of Innovation: towards a theory of innovation and interactive learning (2nd ed., pp. 1-19). London: Pinter Publishers.

Mingoti, S. (2005). Análise de dados através de métodos de estatística multivariada: uma abordagem aplicada. Belo Horizonte: Editora UfMG.

Nelson, R. R., \& Rosenberg, N. (1993). Technical innovation and national systems. In R. Nelson (Ed.), National Innovation Systems (pp. 3-21). New York, Oxford: Oxford University Press.

Oinas, P., \& Malecki, E. (1999). Spatial Innovation Systems. In E. Malecki \& P. Oinas (Eds.), Making connections: Technological learning and regional economic change. Aldershot: Ashgate.

Oreiro, J. L., \& Feijó, C. a. (2010). Desindustrialização: conceituação, causas, efeitos e o caso brasileiro. Revista de Economia Política, 30(2), 219-232. http://doi.org/10.1590/ S0101-31572010000200003

Ribeiro, L., Ruiz, R., Bernardes, A., \& Albuquerque, E. (2006). The curse of technological race: the red queen effect (Textos para Discussão No. 288). Belo Horizonte.

Santos, U. P. dos. (2014). A dimensão espacial da sistema nacional de inovaçâa e seus impactos regionais na economia brasileira. Tese de doutoramento, Belo Horizonte. 


\section{Anexo 1}

FIGURA AI | Regióes e Unidades Federativas do Brasil

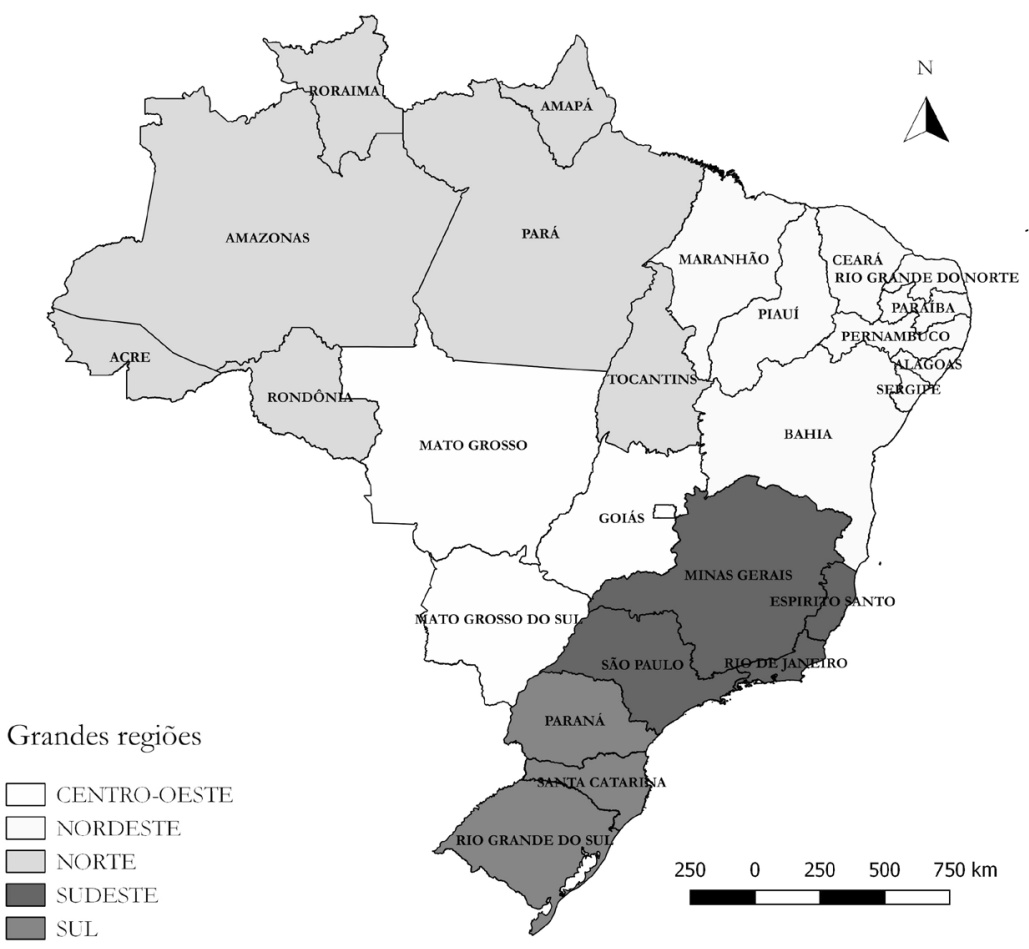

FONTE ELABORAÇÃO PRÓPRIA A PARTIR DE DADOS DO IBGE 


\section{Anexo A2}

TABEla A2.I | Teste de Hausman: Determinantes da dinâmica do setor de serviços

\begin{tabular}{l|c|c|c|c}
\multirow{2}{*}{} & \multicolumn{2}{|c|}{ COEFICIENTES } & & \\
\cline { 2 - 5 } & $(\mathbf{B})$ & $(\mathbf{B})$ & $(\mathbf{B}-\mathbf{B})$ & $\begin{array}{c}\text { SQRT } \\
\text { (DIAG(V_B-V_B) })\end{array}$ \\
\cline { 2 - 5 } & $\mathbf{F E}$ & $\mathbf{R E}$ & DIFFERENCE & S.E. \\
\hline IDRSI & 0,0102 & 0,1994 & $-0,1892$ & 0,0685 \\
\hline PIB industrial (per capta) & $-0,0264$ & 0,0670 & $-0,0933$ & 0,0196 \\
\hline PIB (per capta) vizinhos & 0,5655 & 0,5240 & 0,0415 & 0,0218 \\
\hline Exportaçōes (per capta) & 0,0002 & 0,0002 & 0,0000 & 0,0000 \\
\hline Exportações (per capta) vizinhos & $-0,0001$ & $-0,0001$ & 0,0000 & 0,0000 \\
\hline PIB industrial (per capta) vizinhos & $-0,4125$ & $-0,3980$ & $-0,0145$ & 0,0540 \\
\hline
\end{tabular}

$\mathrm{b}=$ consistent under Ho and $\mathrm{Ha}$; obtained from xtreg

$\mathrm{B}=$ inconsistent under $\mathrm{Ha}$, efficient under Ho; obtained from xtreg

Test: Ho: difference in coefficients not systematic

$\operatorname{chi} 2(5)=(b-B)^{\prime}\left[\left(V_{-} b-V \_B\right)^{\wedge}(-1)\right](b-B)$

$=37.37$

Prob $>$ chi $2=0.0000$

FONTE ELABORAÇÃO PRÓPRIA COM BASE EM IBGE, MDIC, ISI, INPI E GEOCAPES

TABEla A2.2 |Teste de Hausman: Determinantes da dinâmica do setor industrial

\begin{tabular}{l|c|c|c|c}
\multirow{2}{*}{} & \multicolumn{4}{|c}{ COEFICIENTES } \\
\cline { 2 - 5 } & $(\mathbf{B})$ & $(\mathbf{B})$ & $(\mathbf{B}-\mathbf{B})$ & $\begin{array}{c}\text { SQRT } \\
\text { (DIAG(V_B-V_B }))\end{array}$ \\
\cline { 2 - 5 } & $\mathbf{F E}$ & $\mathbf{R E}$ & DIFFERENCE & S.E. \\
\hline IDRSI & 0,1075 & 0,1221 & $-0,0146$ & 0,0991 \\
\hline PIB (per capta) vizinhos & 0,0386 & 0,0538 & $-0,0152$ & 0,0332 \\
\hline Exportaçôes (per capta) & 0,0003 & 0,0003 & 0,0000 & 0,0000 \\
\hline Exportaçốes (per capta) vizinhos & $-0,0002$ & $-0,0002$ & 0,0000 & 0,0000 \\
\hline PIB industrial (per capta) vizinhos & 0,6988 & 0,5833 & 0,1156 & 0,0791 \\
\hline
\end{tabular}

$\mathrm{b}=$ consistent under Ho and Ha; obtained from xtreg

$\mathrm{B}=$ inconsistent under $\mathrm{Ha}$, efficient under $\mathrm{Ho}$; obtained from xtreg

Test: Ho: difference in coefficients not systematic

chi2 $(5)=(b-B)^{\prime}\left[\left(V \_b-V \_B\right)^{\wedge}(-1)\right](b-B)$

$=4.26$

Prob $>$ chi $2=0.3715$

FONTE ELABORAÇÃo PRÓPRIA COM BASE EM IBGE, MDIC, ISI, INPI E GEOCAPES 